\title{
Severe aplastic anemia preceding acute monocytic leukemia in an adult with acquired trisomy 21: A case report
}

\author{
DONGMEI GUO, QINQIN LIU, BANBAN LI and QINGLIANG TENG \\ Department of Hematology, The Central Hospital of Taian, Taian, Shandong 271000, P.R. China
}

Received May 10, 2013; Accepted November 19, 2013

DOI: $10.3892 / 01.2013 .1724$

\begin{abstract}
The current case report presents a patient with acute monocytic leukemia (AML-M5) occurring 14 years following the successful treatment of severe aplastic anemia (SAA) with immunosuppressants and androgens. The patient was treated with induction chemotherapy, but did not achieve remission. The patient succumbed to central nervous system bleeding 2 weeks following the first cycle of chemotherapy. Chromosomal examination revealed $47, \mathrm{XX},+21[10] / 46, \mathrm{XX}[1]$. To the best of our knowledge the present case is the first to be reported of SAA 14 years preceding AML-M5 with acquired trisomy 21.
\end{abstract}

\section{Introduction}

Aplastic anemia (AA) is a clinical syndrome of peripheral blood pancytopenia and a hypocellular bone marrow. Immunosuppressive therapy is a key treatment strategy for AA. Genomic instability in AA does not appear to be a rare event. AA evolves into acute myeloid leukemia (AML) in $5-15 \%$ of all cases $(1,2)$. Careful observation for leukemic transformation is indicated in patients with severe AA (SAA). Trisomy 21 is relatively common in Down syndrome, but rare in secondary AML. The current report presents the first case of SAA preceding acute monocytic leukemia (AML-M5) with acquired trisomy 21 . Written informed consent was obtained from the patient's family.

\section{Case report}

A 20-year-old female was admitted to the Department of Hematology, The Central Hospital of Taian (Taian, China) in May 1996 with fever, dizziness and increasing tiredness. The patient exhibited no other positive medical or family history of any specific disease. In addition, the patient did not exhibit any features of Down syndrome. On physical examination, the

Correspondence to: Professor Qingliang Teng, Department of Hematology, The Central Hospital of Taian, 29 Longtan Road, Taian, Shandong 271000, P.R. China

E-mail: tatql@163.com

Key words: severe aplastic anemia, leukemia, trisomy 21 patient was severely ill, pale and covered with mucocutaneous petechial bleeding. No lymphadenopathy or hepatosplenomegaly was observed. Viral serology was negative for hepatitis A, B and $\mathrm{C}$, as well as human immunodeficiency virus. On full blood count, hemoglobin ( $\mathrm{Hb}$ ) count was $78 \mathrm{~g} / \mathrm{l}$, white blood cell count was $0.7 \times 10^{9} / 1$, platelet count was $16 \times 10^{9} / 1$, neutrophil count was $0.46 \times 10^{9} / 1$ and reticulocyte count was $0.6 \%$. Bone marrow aspirate was profoundly hypocellular and no megakaryocytes were observed. No mast cells, but a few foci of plasma cells and lymphocytes were identified. Residual myeloid and erythroid precursors were observed without any abnormal infiltrate. The patient was diagnosed with SAA.

The individual was treated with intravenous broad-spectrum antibiotics and multiple red cell and platelet transfusions with resolution of the fever, dizziness and increasing tiredness. The patient received, with high-dose methylprednisolone, cyclosporine A, androgens and recombinant human granulocyte colony-stimulating factor (G-CSF). Two years later, the blood counts returned to normal and the patient gradually stopped receiving drug therapy.

In 2001, the patient delivered a normal child. However, the results of the patients routine blood test were abnormal; the platelet count was $<10 \times 10^{9} / 1$ and $\mathrm{Hb}$ levels were also decreased. The patient received blood and platelet transfusions without other drug treatment.

In October 2010, the patient was hospitalized due to nasal bleeding and mild headache. On full blood count, white blood cell count was $19.92 \times 10^{9} / 1$, neutrophil count was $5.89 \times 10^{9} / 1$, monocyte count was $2.09 \times 10^{9} / 1$, Hb count was $105 \mathrm{~g} / 1$, platelet count was $20 \times 10^{9} / 1$ and the reticulocyte count was $4.27 \%$. Blast cells were observed on blood film and the bone marrow smears showed an increased number (31\%) of monoblasts and promonocytes. Blast cells stained negatively for PAS and specific esterase stain and positive for non-specific esterase, which was inhibited by sodium fluoride. These observations were compatible with AML-M5b and chromosomal examination revealed 47,XX,+21[10]/46,XX[1] (Fig. 1). The patient was treated with induction chemotherapy, but did not achieve remission. The patient succumbed to central nervous system bleeding 2 weeks following chemotherapy.

\section{Discussion}

Leukemia is a rare and late complication of AA. AML and myelodysplasia syndromes (MDS) occur in $15 \%$ of patients 


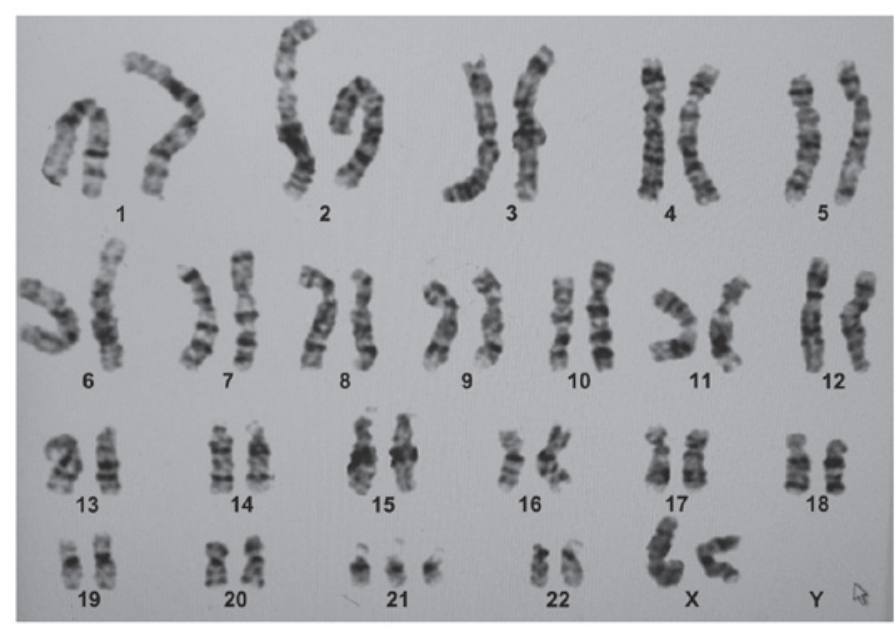

Figure 1. Chromosomal analysis.

within 10 years following immunosuppressive treatment (3). There have been various reasons proposed as to why AA may precede AML. Previously, Barrios et al (4) presented a patient with SAA, with no previous chromosomal abnormalities, who developed trisomy 21 and monosomy 7 during treatment with intravenous cyclosporine. The abnormal karyotype disappeared when the drug was changed to the oral form. Furthermore, the published data on the safety of G-CSF for AA remain controversial. It has been reported that G-CSF therapy does not increase the risk of t-MDS/AML development (5-7). However, specific results have shown that G-CSF therapy is one of the risk factors for AA evolution to MDS/AML (8-10). Further studies are required to identify the risk factors in SAA for developing MDS/AML.

The evolution of AA to clonal hematologic diseases is well recognized. Cytogenetics are usually normal in the aplastic phase, but abnormalities may develop in the leukemic phase. The current report presents a new case of SAA preceding AML with trisomy 21 as the sole acquired karyotypic abnormality.

Trisomy 21 has been demonstrated to be a recurring cytogenetic abnormality in AML and MDS. Trisomy may contribute to leukemogenesis by a gene dosage effect. The majority of adult AML cases with trisomy 21 have been associated with AML-M2 or -M4 (11). By comparison, the most common hematological malignancy in patients with Down syndrome is AML-M7 $(8,12)$. The prognostic significance of acquired trisomy 21 as the sole abnormality in adult AML remains unclear. A higher complete remission has previously been reported in AML with trisomy 21 (13), but a study showed that other accompanied cytogenetic changes determined the clinical outcome (14). In addition, a greater number of studies have shown that AML patients with acquired trisomy 21 as the sole abnormality exhibit a poor prognosis (14-16). Therefore, further studies with larger cohorts of patients are required to evaluate the prognostic significance of acquired trisomy 21.

The course and prognosis of secondary leukemia depends on not only cytogenetic features, but also clinical and molecular features at diagnosis. Previously, the successful therapy of such secondary leukemia has been rarely reported. Patients have not responded or have succumbed to infection or bleeding during induction. Irreversible aplasia is a hazard of intensive chemotherapy. Fatal bleeding events eventually occurred in the present patient, who was refractory to platelet transfusions.

Cytomorphological and cytogenetic abnormalities are rarely observed in AA, which may predict patients with SAA at risk for leukemia. Prior to the diagnosis of AML, SAA patients may develop signs of MDS. Therefore, long-term follow-up is essential to assess the incidence and risk factors for evolution of AA into AML, and to administer salvage therapy for transformation, in time, during follow-up. In addition, the best supportive care must be fully integrated with diagnosis and treatment. For example, multiple anti-human leukocyte antigen (HLA) antibodies must be detected prior to the initiation of chemotherapy and appropriate, unrelated HLA-matched platelet donors must be selected prior to therapy in patients who were refractory to platelet transfusions (17). In conclusion, an increased number of factors must be considered when determining the most appropriate management of such secondary leukemia. This remains an unsatisfactory area with the greatest clinical challenge in secondary AML.

\section{Acknowledgements}

The present study was supported by grants from the Shandong Province Natural Science Foundation of China (nos. 2009ZRA09006 and ZR2012HL38) and the Shandong Province Medical Science and Technology Development Program (no. 2011HW077).

\section{References}

1. Ohara A, Kojima S, Hamajima N, et al: Myelodysplastic syndrome and acute myelogenous leukemia as a late clonal complication in children with acquired aplastic anemia. Blood 90: 1009-10013, 1997.

2. Barrett J, Saunthararajah Y and Molldrem J: Myelodysplastic syndrome and aplastic anemia: distinct entities or diseases linked by a common pathophysiology? Semin Hematol 37: 15-29, 2000.

3. Tichelli A, Gratwohl A, Nissen C and Speck B: Late clonal complications in severe aplastic anemia. Leuk Lymphoma 12: 167-175, 1994.

4. Barrios NJ, Kirkpatrick DV, Levin ML and Varela M: Transient expression of trisomy 21 and monosomy 7 following cyclosporin A in a patient with aplastic anemia. Leuk Res 15: 531-533, 1991. 
5. Locasciulli A, Arcese W, Locatelli F, Di Bona E and Bacigalupo A; Italian Aplastic Anaemia Study Group: Treatment of aplastic anaemia with granulocyte-colony stimulating factor and risk of malignancy: Italian Aplastic Anaemia Study Group. Lancet 357: 43-44, 2001.

6. Imashuku S, Hibi S, Bessho F, et al: Detection of myelodysplastic syndrome/acute myeloid leukemia evolving from aplastic anemia in children, treated with recombinant human G-CSF. Haematologica 88: ECR31, 2003.

7. Gurion R, Gafter-Gvili A, Paul M, et al: Hematopoietic growth factors in aplastic anemia patients treated with immunosuppressive therapy - systematic review and meta-analysis. Haematologica 94: 712-719, 2009.

8. Kojima S, Ohara A, Tsuchida M, et al: Risk factors for evolution of acquired aplastic anemia into myelodysplastic syndrome and acute myeloid leukemia after immunosuppressive therapy in children. Blood 100: 786-790, 2002.

9. Sloand EM, Yong AS, Ramkissoon S, et al: Granulocyte colony-stimulating factor preferentially stimulates proliferation of monosomy 7 cells bearing the isoform IV receptor. Proc Nat Acad Sci USA 103: 14483-14488, 2006.

10. Socie G, Mary JY, Schrezenmeier H, Marsh J, et al: Granulocyte-stimulating factor and severe aplastic anemia: a survey by the European Group for Blood and Marrow Transplantation (EBMT). Blood 109: 2794-2796, 2007.

11. Wang HF, Cheng YZ, Wang HP, Chen ZM, Lou JY and Jin J: CD19-positive acute myeloblastic leukemia with trisomy 21 as a sole acquired karyotypic abnormality. J Zhejiang Univ Sci B 10: 833-838, 2009.
12. Langebrake C, Creutzig U and Reinhardt D: Immunophenotype of Down syndrome acute myeloid leukemia and transient myeloproliferative disease differs significantly from other diseases with morphologically identical or similar blasts. Klin Padiatr 217: 126-134, 2005.

13. Udayakumar AM, Pathare AV, Muralitharan S, Alghzaly AA, Alkindi S and Raeburn JA: Trisomy 21 as a sole acquired abnormality in an adult Omani patient with CD7- and CD9-positive acute myeloid leukemia. Arch Med Res 38: 797-802, 2007.

14. Cortes JE, Kantarjian H, O'Brien S, et al: Clinical and prognostic significance of trisomy 21 in adult patients with acute myelogenous leukemia and myelodysplastic syndromes. Leukemia 9: 115-117, 1995 .

15. Wan TS, Au WY, Chan JC, Chan LC and Ma SK: Trisomy 21 as the sole acquired karyotypic abnormality in acute myeloid leukemia and myelodysplastic syndrome. Leuk Res 23: 1079-1083, 1999.

16. Wang H, Ni W, Chen Z, et al: Clinical and cytogenetic features of hematologic malignancies associated with acquired trisomy 21. Zhonghua Yi Xue Yi Chuan Xue Za Zhi 25: 576-578, 2008 (In Chinese).

17. Xia WJ, Ye X, Tian LW, et al: Establishment of platelet donor registry improves the treatment of platelet transfusion refractoriness in Guangzhou region of China. Transfus Med 20: 269-274, 2010. 